\title{
Proposta de metodologia para classificação de empresas de transporte rodoviário de combustíveis líquidos
}

\author{
Marne Lieggio Júnior ${ }^{1}$; Carmen L. E. da Fonseca Caixeta ${ }^{2}$; Marcos Paulo Bogossian ${ }^{3}$; \\ Sérgio Ronaldo Granemann ${ }^{4}$
}

\begin{abstract}
Resumo: O objetivo deste trabalho consiste em propor uma metodologia de classificação de empresas de transporte rodoviário de combustíveis líquidos, de forma a oferecer ao embarcador uma ferramenta de apoio à tomada de decisão, no processo de contratação de uma transportadora. A metodologia de classificação é construída a partir da visão de três grupos de atores: os transportadores de combustível líquido, técnicos da Agência Nacional de Transportes Terrestres - ANTT e especialistas em transporte e logística. Os atributos da oferta de serviço importantes para o transporte rodoviário de combustíveis líquidos levantados junto aos grupos de atores entrevistados deram suporte à elaboração da proposta metodológica.
\end{abstract}

Abstract: The goal of this work consists in to propose to companies of road transport of liquid fuels a classification methodology to offer to the shipper a support tool to the decision outlet, in the contract process of a transport. The classification methodology is built from the vision of three actors' groups: the transporter of liquid fuels, technical people from the National Agency of Terrestrial Transport - ANTT and specialists in transportation and logistics. The offer attributes of important service for the road transport of liquid fuels obtained close to the actors' groups interviewees gave support to the elaboration of the methodological proposal.

\section{INTRODUÇÃO}

Os combustíveis líquidos, oriundos de fontes renováveis ou não, representam mais de $40 \%$ da matriz energética brasileira, e a evolução do crescimento do transporte rodoviário desse tipo de carga acompanha o ritmo de crescimento dos setores de transporte e da indústria, responsáveis, respectivamente, por $61 \% \mathrm{e}$ $6,90 \%$ do consumo total de energia processada no Brasil (EPE, 2006). Essa evolução está intrinsecamente associada ao crescimento da produção de petróleo e de fontes renováveis de energia, como, por exemplo, o álcool e os biocombustíveis.

O Departamento de Energia dos EUA realiza previsões de oferta e demanda para os próximos 25 anos para a produção de petróleo e prevê sua participação na matriz energética mundial em torno de $40 \%$ (EIA, 2005). O Departamento prevê, ainda, a manutenção do crescimento da demanda de petróleo em níveis elevados $(1,90 \%$ ao ano) até 2025 , puxada pelo setor de

\footnotetext{
${ }^{1}$ Marne Lieggio Júnior, Departamento de Engenharia Civil e Ambiental, Universidade de Brasília. Brasília, DF, Brasil. (e-mail: marnej@@gmail.com).

${ }^{2}$ Carmen L. E. da Fonseca Caixeta, Departamento de Engenharia Civil e Ambiental, Universidade de Brasília. Brasília, DF, Brasil. (email:

clcaixeta@hotmail.com).

${ }^{3}$ Marcos Paulo Bogossian, Departamento de Engenharia Civil e Ambiental, Universidade de Brasília. Brasília, DF, Brasil. (e-mail: mpbogossian@terra.com.br).

${ }^{4}$ Sérgio Ronaldo Granemann, Departamento de Engenharia Civil e Ambiental, Universidade de Brasília. Brasília, DF, Brasil. (e-mail: sergiog@unb.br).
}

transporte e pelos países em desenvolvimento, em particular pela China e Índia. Não obstante, somente no Brasil, a produção de álcool, no período compreendido entre 2004 e 2005 , cresceu mais de 9,50\% (ANP, 2006).

No entanto, não somente a pujança econômica caracteriza a atividade de transporte rodoviário de combustíveis líquidos, mas, sobretudo, as vulnerabilidades a que ficam submetidos o homem, a população exposta (principalmente a lindeira às vias) e o meio ambiente, além, é claro, de prejuízos decorrentes de perda de carga, patrimônio privado (entre eles, veículos), danos à infra-estrutura viária pública e dificuldades na gestão da operação do tráfego das vias.

Nesse contexto, o objetivo deste trabalho consiste na proposição de uma metodologia de classificação de empresas de transporte rodoviário de combustíveis líquidos, que permita uma seleção mais adequada dos transportadores e uma redução do risco estratégico associado à escolha e da vulnerabilidade a que se expõem os vários elementos dessa cadeia produtiva.

Além disso, a metodologia procura incluir a avaliação de critérios que contribuem para o aumento da vantagem competitiva por parte das empresas contratantes e contratadas, uma vez que considera parâmetros de qualidade nos serviços de transporte prestados. Também, incorpora critérios relacionados ao equilíbrio ecológico, estimulando o uso de tecnologias gerenciais e operacionais limpas. 


\section{O TRANSPORTE RODOVIÁRIO DE COMBUSTÍVEIS LÍQUIDOS}

\subsection{O conceito de produto perigoso}

De acordo com a Resolução ANTT no 420/2004 (ANTT, 2004), que aprova as Instruções Complementares ao Regulamento do Transporte Terrestre de Produtos Perigosos, é denominado produto perigoso, toda substância ou artigo encontrado na natureza ou produzido por qualquer processo que, por suas características físico-químicas, represente risco para saúde das pessoas, para a segurança pública ou para o meio ambiente.

\subsection{A vulnerabilidade no transporte rodoviário de combustíveis líquidos}

Segundo Hartman (2003), as metodologias mais usuais de análise de vulnerabilidade decorrente do transporte rodoviário de produtos perigosos são baseadas na investigação de riscos, conforme a seguinte equação:

Risco $=$ Probabilidade de acidentes $\cdot$ Conseqüencia

Outros autores, como Rhyne (1994), Harwood et al. (1990), Scalon e Cantilli (1985) e Pijawka (1985), trabalharam com a avaliação de rotas de menor risco no transporte de produtos perigosos tomando como base a equação (1).

Os estudos de Verter e Kara (2001), Gheorghe (2006) e Porath et al. (2005) podem ser destacados na abordagem de transporte de produtos perigosos, com ênfase no uso de modelagens multicritérios, enfocando, sobretudo, parâmetros de tráfego, com o apoio de ferramentas do tipo GIS (Geographic Information System).

De uma maneira geral, tais estudos fundamentam-se nos seguintes parâmetros: (a) vulnerabilidade do ambiente rodoviário e de seu entorno, englobando fatores de conflitos potenciais com a população lindeira, com os recursos naturais do entorno, com a geometria e a operação da rodovia e com o suporte emergencial local, que afetam sobremaneira a gestão do tráfego na via; (b) periculosidade das substâncias determinada para cada segmento rodoviário em função das características físico-químicas e das quantidades transportadas de cada tipo de produto; (c) freqüencia desse transporte em termos do número de viagens realizadas por mês; e (d) probabilidade de um tanque apresentar vazamento, dado que houve acidente com a unidade de transporte ou de carga.

Contudo, não foram encontrados, na pesquisa bibliográfica realizada, estudos específicos que considerem a adequação da escolha da transportadora para a movimentação dos combustíveis líquidos, como uma estratégia de redução do risco.

\subsection{Acidentes no transporte rodoviário de combustíveis líquidos}

Segundo Ramos (1997), o planejamento para a prevenção dos acidentes com produtos perigosos deve ocorrer nas várias fases do processo: produção, transporte, transformações, utilização e disposição final. Porém, a etapa de maior vulnerabilidade é o transporte, pois nele a carga é exposta a situações em que se torna capciosa a prevenção ou o controle dos riscos devido a fatores adversos, tais como: acidentes com outros veículos, condições do transporte e do trânsito, traçado da pista e de sua manutenção, habilidade e condição do motorista, condições atmosféricas etc. São também importantes os possíveis efeitos danosos sobre a comunidade e a biota local, o que faz com que se acentue a necessidade de controle desses riscos durante o transporte desse tipo de produto.

Lieggio Júnior (2006) mostra que a movimentação da produção dos setores químico, petroquímico e de refino de petróleo, entre outros, é feita na sua maioria por rodovias. Por conseguinte, essa atividade lidera as estatísticas de acidentes ambientais, com 2.399 acidentes, ou seja, $38,1 \%$ do total de acidentes ocorridos no Estado de São Paulo entre 1978 e 2005 (CETESB, 2007), conforme ilustrado na Tabela 1.

Cabe destacar que o transporte rodoviário foi res-

Tabela 1. Atendimentos emergenciais realizados pela CETESB no período entre 1978 e 2006

\begin{tabular}{|c|c|c|c|c|c|c|}
\hline Atividades & $\begin{array}{c}\text { Atendimentos } \\
1978 \text { a } 2005 \\
\end{array}$ & \% 1978 a 2005 & $\begin{array}{c}\text { Atendimentos } \\
2005 \\
\end{array}$ & $\% 2005$ & $\begin{array}{c}\text { Atendimentos } \\
2006 \\
\end{array}$ & $\% 2006$ \\
\hline Armazenamento & 164 & 2,4 & 15 & 3,6 & 11 & 2,8 \\
\hline Descarte de produtos químicos & 308 & 4,9 & 28 & 6,7 & 30 & 7,6 \\
\hline Indústria & 461 & 7,3 & 26 & 6,2 & 30 & 7,6 \\
\hline Mancha órfã & 103 & 1,6 & 3 & 0,7 & 10 & 2,5 \\
\hline Não constatado & 639 & 10,1 & 26 & 6,2 & 15 & 3,8 \\
\hline Não identificada & 304 & 4,8 & 31 & 7,4 & 26 & 6,5 \\
\hline Outras & 776 & 12,3 & 40 & 9,5 & 34 & 8,5 \\
\hline Postos e sist. Retalhistas de combustíveis & 586 & 9,3 & 36 & 8,6 & 22 & 5,5 \\
\hline Transporte ferroviário & 60 & 1,0 & 4 & 1,0 & 8 & 2,0 \\
\hline Transporte marítimo & 329 & 5,2 & 7 & 1,7 & 9 & 2,3 \\
\hline Transporte por duto & 174 & 2,8 & 6 & 1,4 & 4 & 1,0 \\
\hline Transporte rodoviário & 2.399 & 38,1 & 197 & 47,0 & 198 & 49,9 \\
\hline TOTAL & 6.303 & 100 & 419 & 100 & 397 & 100 \\
\hline
\end{tabular}

Fonte: (CETESB, 2007) 
ponsável por $49,9 \%$ do total dos atendimentos emergenciais ocorridos em 2006 no Estado de São Paulo (Tabela 1).

E, ainda, de acordo com estudos da CETESB (2007), os líquidos inflamáveis detiveram a participação de 57,01\% nos acidentes no transporte rodoviário de produtos perigosos ocorridos nas rodovias estaduais paulistas, segundo classes de produtos transportados, considerado o período entre 1997 e 1999.

$\mathrm{O}$ expressivo índice de atendimentos emergenciais realizados pela CETESB no modo rodoviário, envolvendo principalmente líquidos inflamáveis, torna premente a necessidade da dedicação a estudos de vulnerabilidade, de modo a contribuir para a geração de ambientes de tráfego mais seguros e eficientes.

\section{A LOGÍSTICA DO TRANSPORTE RODOVIÁRIO DE COMBUSTÍVEIS LÍQUIDOS}

A cadeia logística do transporte de combustíveis líquidos engloba os agentes relacionados à produção, distribuição, varejo e consumo, conforme ilustra a Figura 1. Os agentes produtores são constituídos pelas refinarias, centrais petroquímicas, usinas de álcool, produtores de biodiesel e importadores. As bases distribuidoras alimentam a rede varejista, composta pelos postos revendedores e Transportadores Revendedores Retalhistas (TRRs). Já os postos revendedores são responsáveis pelo abastecimento de automobilistas e caminhoneiros, e os TRRs, pelas pequenas empresas consumidoras e produtores em geral. Os importadores, por sua vez, garantem o fornecimento aos grandes consumidores.

A Tabela 2 traz um quantitativo dos vários agentes relacionados aos processos de produção, distribuição e consumo de combustíveis líquidos.

As bases de distribuição primárias ou principais têm
Tabela 2. Principais números do setor

\begin{tabular}{lrl}
\hline & 14 & Refinarias \\
Produção & 3 & Centrais Petroquímicas \\
& 317 & Usinas de álcool \\
& 22 & Produtores de biodiesel \\
& 214 & Importadores \\
\hline Distribuição & 265 & Distribuidoras \\
\hline \multirow{3}{*}{ Varejo } & 34.300 & Postos revendedores \\
& 470 & Transportador Revendedor \\
& & Trabalhista (TRR) \\
\hline \multirow{2}{*}{ Consumidor } & & Grandes consumidores \\
& & Consumidores rurais \\
& & Peq. Empresas consumidoras \\
& & Caminhoneiros \\
& & Automobilistas \\
\hline
\end{tabular}

como característica o recebimento dos produtos diretamente das refinarias ou por meio de importação. As bases secundárias ou de interior são caracterizadas por receberem o produto de outra base, seja principal, seja secundária. A Figura 2 apresenta a localização geográfica das bases de distribuição de combustíveis líquidos e seus modos de transporte de recebimento e despacho de produtos.

Das refinarias, os produtos seguem para as bases primárias das distribuidoras, o que, atualmente e em sua maior parte, segundo Dumit (2005), é realizado pelo modo dutoviário, para as regiões Sul e Sudeste; e por navegação de cabotagem, para as bases localizadas no litoral do Nordeste brasileiro. Já as transferências entre as instalações das bases primárias e secundárias são realizadas pelo modo rodoviário (caminhões-tanque) e modo ferroviário (vagões-tanque).

O grande desafio logístico que as distribuidoras enfrentam é o de disponibilizar os seus produtos nos pontos mais longínquos do Brasil, com qualidade e preços competitivos. Para vencer as dimensões brasileiras, as principais distribuidoras mantêm bases em diversas regiões, cujas instalações possuem toda a infra-estrutura necessária para receber, armazenar, misturar, embalar e distribuir os combustíveis e seus deri-

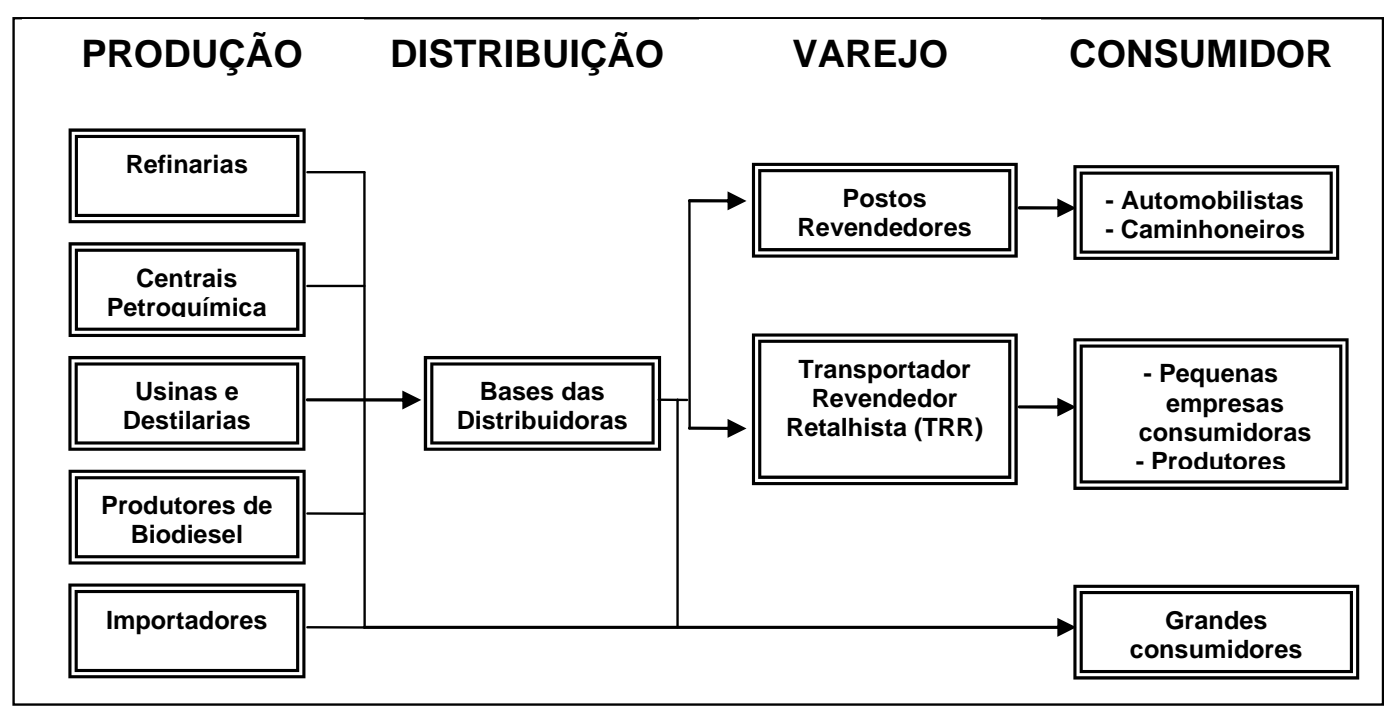

Figura 1. Esquema do fluxo logístico do transporte rodoviário de combustíveis líquidos no Brasil 


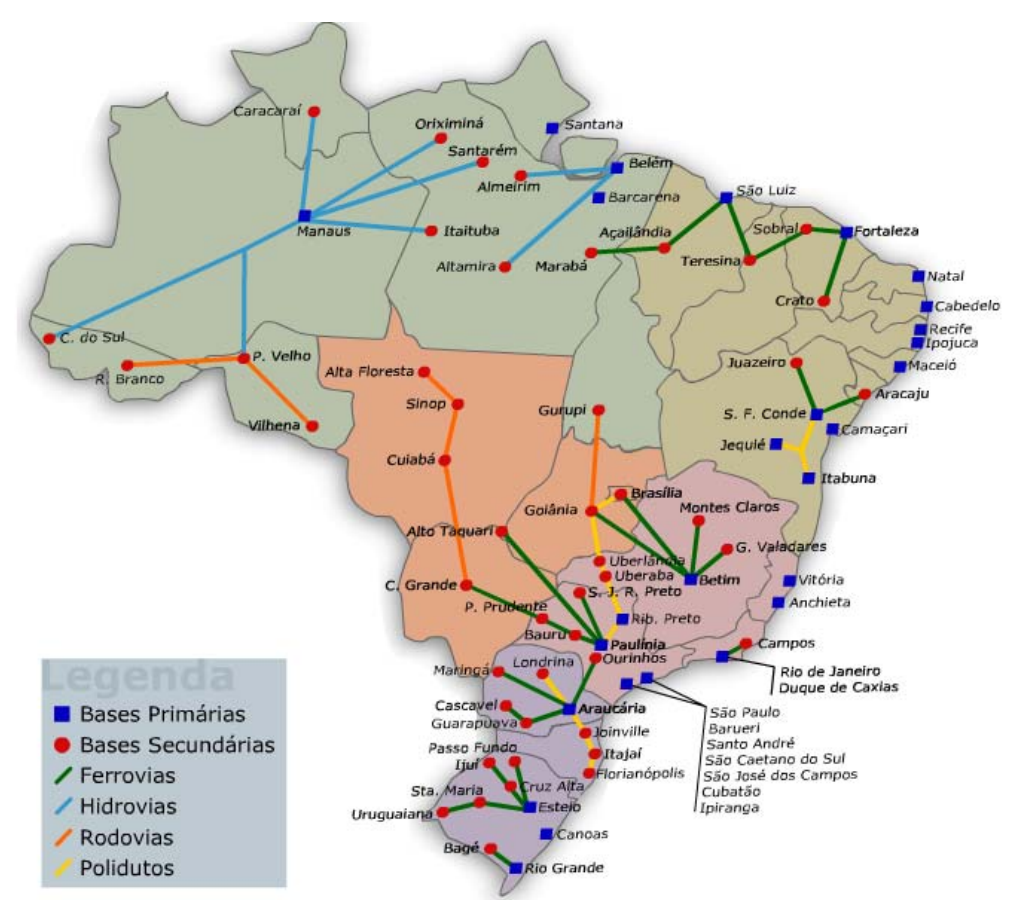

Figura 2. Representação geográfica das bases de distribuição de combustíveis líquidos no Brasil e suas ligaçães nos modos de transporte rodo, ferro, hidro e dutoviário. Fonte: SINDICON (2007)

vados. As bases podem ser categorizadas em: próprias, quando todos os ativos pertencem a uma determinada distribuidora; pools, em que cada distribuidora participa com um percentual de investimento; e bases operadas por terceiros, nas quais as distribuidoras não possuem ativos, somente os produtos a serem movimentados por terceiros, no caso as transportadoras.

\section{METODOLOGIA}

O presente trabalho baseou-se no esquema metodológico apresentado na Figura 3.

Primeiramente, foi feito um trabalho de levantamento e identificação das informações (inputs) relevantes para o transporte de combustíveis líquidos. Esse levantamento teve como alicerce pesquisas de qua- tro categorias e visou à identificação dos critérios importantes para a escolha do transportador: (a) levantamento da legislação existente sobre transporte de combustíveis líquidos - exigências legais; (b) revisão bibliográfica sobre o tema; (c) estudo das práticas comerciais atualmente utilizadas pelas empresas; e (d) opinião de um conjunto de especialistas em transporte e logística. Com isso, foi possível realizar a identificação; a estratificação; e a valoração dos critérios, através da escala de Likert. Em seguida, passou-se ao estudo de caso, em que se apresentou a análise dos resultados.

\section{Exigências legais ou critérios não negociáveis}

As exigências legais baseiam-se no arcabouço jurídico

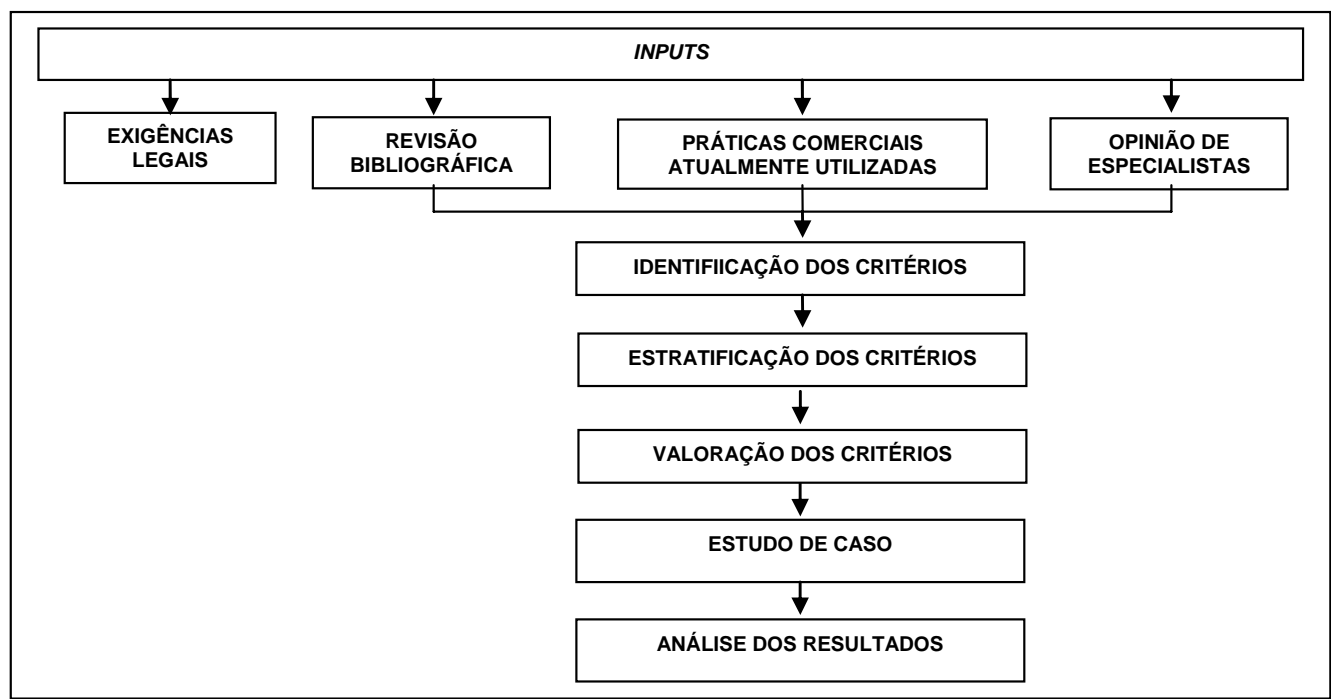

Figura 3. Esquema metodológico empregado 
que rege o serviço de transporte rodoviário de produtos perigosos a granel, dentre os quais podem ser destacados:

- Decreto-Lei no 2.068/83: dispõe sobre multas a serem aplicadas por infrações à regulamentação para a execução dos serviços de transporte de cargas ou produtos perigosos.

- Lei no 9.605/98: dispõe sobre as sanções penais e administrativas de condutas e atividades lesivas ao meio ambiente.

- Decretos nos 96.044/88 e 1.797/96: versam sobre o Regulamento do Transporte Rodoviário de Produtos Perigosos (RTRPP) no âmbito nacional, determinando exigências quanto a informações constantes no documento fiscal; porte obrigatório de documentos; sinalização das unidades de transporte e de carga; porte de equipamentos de segurança e de emergência; certificação de embalagens; certificação de inspeção de veículos e equipamentos destinados ao transporte a granel; e curso específico para condutores.

- Portaria MT nos 349/02: rege as instruções de fiscalização do TRPP no âmbito nacional.

- Resoluções ANTT nos 420/04, 701/04 e 1644/06: constituem instruções complementares ao RTRPP.

- Portarias Inmetro: determinam regulamentos técnicos de qualidade e de avaliação da conformidade para embalagens e veículos e equipamentos destinados ao transporte rodoviário de produtos perigosos a granel.

- Resolução Contran no 168/04: regulamenta o curso específico para condutores de veículos transportadores de produtos perigosos.

\section{Práticas comerciais atualmente utilizadas e opinião de especialistas}

Para identificação das práticas comerciais utilizadas no mercado, foram entrevistadas cinco grandes empresas que tanto ofertam quanto demandam serviços de transporte rodoviário de combustíveis líquidos, responsáveis pela movimentação de mais $68,5 \%$ da movimentação no mercado brasileiro (SINDICON, 2007).

Para a identificação dos critérios considerados relevantes para o transporte de combustíveis líquidos, além das empresas consultadas, foram entrevistados dois grupos de especialistas: dez técnicos da área de regulação de transporte de produtos perigosos da ANTT, que representam o contingente total nessa área específica, e trinta especialistas em transporte e logística.

\section{Identificação, estratificação e valoração de critérios}

Dentre um rol extensivo, o grupo de pesquisadores elegeu trinta e sete critérios, os quais foram dispostos em quatro classes de aspectos: administrativos, operacionais e de segurança, econômicos e de meio ambiente.

Foi elaborado um questionário aberto, consistindo de duas questões. A primeira solicitava aos três grupos distintos que valorassem, primeiramente, os quatro aspectos apresentados, utilizando-se a escala de Likert (Likert, 1967), conforme a Tabela 3. Na segunda questão, apresentava-se a lista dos trinta e sete critérios, classificados nos quatro aspectos considerados, e pedia-se que, dentre os critérios listados, fossem eleitos dez que julgassem mais importantes e avaliassem, com base na mesma escala.

Tabela 3. Graus de importância na escala de Likert

\begin{tabular}{ccccc}
\hline \multicolumn{4}{c}{ Grau de importância } \\
$\begin{array}{c}\text { Muito } \\
\text { importante }\end{array}$ & Importante & $\begin{array}{c}\text { Mais ou } \\
\text { menos } \\
\text { importante }\end{array}$ & $\begin{array}{c}\text { Pouco } \\
\text { importante }\end{array}$ & $\begin{array}{c}\text { Nada } \\
\text { importante }\end{array}$ \\
\hline 5 & 4 & 3 & 2 & 1 \\
\hline
\end{tabular}

\section{Os critérios resultantes}

Da pesquisa realizada, verificou-se, preliminarmente, que todos os grupos investigados apresentaram a mesma classificação quanto ao grau de importância dado aos aspectos: os operacionais e de segurança estiveram em primeiro lugar, preponderando sobre os de meio ambiente, seguidos dos econômicos e administrativos.

Na seqüência, obteve-se a ordem hierarquizada de critérios para cada grupo pesquisado, conforme mostra a Tabela 4.

O exame da Tabela 4 permite deduzir que os três conjuntos entrevistados elegeram quatro critérios em comum: a confiabilidade no serviço, o Programa de Gerenciamento de Risco, a integridade do produto e os serviços de suporte emergencial.

O discernimento sobre os critérios eleitos denota que o atendimento aos mesmos constitui um importante fator no alcance dos objetivos perseguidos pela corrente legislação e, à medida que se consegue maior grau de desempenho para os mesmos, fortificam-se os atributos de qualidade dos serviços prestados e possibilita-se o crescimento das vantagens competitivas dos transportadores em seu nicho de negócio (Oliveira, 2001).

A sinergia alcançada com a aplicação desses critérios traduz os resultados atuais conquistados pelo mercado, como por exemplo: a redução de $22,95 \%$ do número de acidentes para cada 10.000 viagens, entre 2004 e 2005 (ABIQUIM, 2006), e a redução de $16,56 \%$ do número total de cargas de combustíveis 
Tabela 4. Ordem de classificação dos critérios apurados para os três grupos pesquisados

\begin{tabular}{|c|c|c|c|}
\hline & Grupo 1: transportadores & Grupo 2: técnicos em regulação & Grupo 3: esp. em transp. e logística \\
\hline $1^{\mathrm{o}}$ & Prog. gerenciamento de risco & Programa de gerenciamento de risco & Confiabilidade no serviço \\
\hline $2^{\underline{o}}$ & Prog. qualidade ambiental & Confiabilidade no serviço & Cumprimento dos prazos \\
\hline $3^{\circ}$ & Sistema de rastreamento veicular & Cumprimento dos prazos & Prog. gerenciamento de risco \\
\hline $4^{\circ}$ & Serv. de suporte emergencial & Prog. de capacitação p/ motoristas & Integridade do produto \\
\hline $5^{\circ}$ & Confiabilidade no serviço & Prog. qualidade ambiental & Serv. de suporte emergencial \\
\hline $6^{-}$ & Integridade do produto & Integridade do produto & Tradição no mercado \\
\hline $7^{\circ}$ & Prog. de manutenção da frota & Prog. qual. serviços & $\begin{array}{l}\text { Cuidados com a programação; sistema de } \\
\text { rastreamento veicular }\end{array}$ \\
\hline $8^{o}$ & Realiza a própria descontaminação & $\begin{array}{l}\text { Cuidados com a programação; serv. de } \\
\text { suporte emergencial }\end{array}$ & $\begin{array}{l}\text { Prog. de manutenção da frota; índice de } \\
\text { acidentes }\end{array}$ \\
\hline $9^{\underline{o}}$ & Prog. de seg. e saúde ocupacional & Organização administrativa & Idade média da frota \\
\hline $10^{\mathrm{o}}$ & $\begin{array}{l}\text { Política de renovação da frota; preço } \\
\text { para frete escalonado }\end{array}$ & Índice de acidentes & Abrangência do sistema de atendimento \\
\hline
\end{tabular}

roubadas ou furtadas, no período de 2000 a 2004, diminuindo os decorrentes prejuízos financeiros em mais de 75\% (Guidoni, 2005).

\section{As tabelas de critérios e classificação}

Com os dados obtidos, foi possível estabelecer um procedimento matemático para o cálculo dos pesos para cada aspecto. $\mathrm{O}$ índice $i$ varia de 1 a 3 , designando qual o tipo de grupo pesquisado $(i=1$, transportadores; $i=2$, técnicos da ANTT; e $i=3$, especialistas em transporte e logística). E o índice $j$ assume valores de 1 a 4 , para cada tipo de aspecto $(j=1$, administrativo; $j=2$, operacional e de segurança; $j=3$, econômico; e $j=4$, ambiental).

A nota média calculada para o grupo $i$, considerado o aspecto $j$, foi obtida por meio da expressão (2):

$$
\overline{N A S P}_{j}=\frac{\sum_{i=1}^{3} N A S P_{j} G_{i}}{3}, \text { para } j=1,2,3,4
$$

em que, $\overline{N A S P_{j}}$ : nota média calculada para o aspecto $j$;

$N A S P_{j} G_{i}$ : nota dada pelo grupo $i$ no aspecto

$$
j .
$$

E o peso para cada aspecto $j$ foi calculado por meio da expressão (3):

$$
\operatorname{PASP}_{j}=\frac{\overline{\operatorname{NASP}_{j}}}{\sum_{j=1}^{4} \overline{{N A S P_{j}}_{j}}}
$$

em que, $P A S P_{j}: \quad$ peso para o aspecto $j$;

$\overline{N A S P_{j}}:$ nota média calculada para o as-

$$
\text { pecto } j \text {. }
$$

Os valores para os pesos dos critérios foram conseguidos dividindo-se o peso de cada classe de aspecto pelo número de critérios constantes na mesma.

Para os subcritérios, foram dados pesos em função da gradação do grau de exigência. Assim, para os cri- térios subdivididos em dois subcritérios, tem-se o peso de 1,00 para o de maior grau de exigência e 0,50 para o de menor grau, em relação à nota daquele critério. E, para os critérios subdivididos em três subcritérios: os pesos de 1,00,0,66 e 0,33, respectivamente.

Logo, de posse dos dados e com os pesos calculados, pôde-se, enfim, construir a tabela geral de critérios (Tabela 5).

Tomando-se por base a categorização adotada por algumas embarcadoras consultadas, pôde-se construir a Tabela 6, que representa a classificação das empresas de transporte de combustíveis líquidos em relação ao risco.

\section{ESTUDO DE CASO COM AS TRANSPORTADORAS CONTRATADAS PELA PETROBRAS DISTRIBUIDORA NA REGIÃO CENTRO-OESTE}

A Petrobras Distribuidora foi criada em 1971, subsidiária da Petróleo Brasileiro S.A. - Petrobras, que passou a atuar na comercialização e distribuição de derivados do petróleo para todo o Brasil. Tem posição de liderança no setor; considerável estrutura, com mais de 7.200 postos de serviços, constituindo a maior e única rede de postos presente em todo o território nacional; e mais de 10 mil grandes clientes entre indústrias, termoelétricas, companhias de aviação e frota de veículos leves e pesados.

$\mathrm{Na}$ região Centro-Oeste, a empresa possui uma dezena de transportadoras contratadas que foram avaliadas segundo a metodologia proposta para a classificação de empresas transportadoras de combustíveis líquidos, sendo os resultados expressos na Tabela 6 .

Ancorado em Freitas e Costa (2000), que estudaram a classificação da qualidade de serviços por meio de tratamento multicritério, com o emprego da ferramenta ELECTRE TRI, e com base nos graus de importância dados aos dez principais critérios eleitos pela Petrobras Distribuidora, foi solicitado que a empresa avaliasse o grau de satisfação dos mesmos em relação 
Tabela 5. Tabela geral de critérios para classificação das empresas

TABELA GERAL DE CRITÉRIOS PARA CLASSIFICAÇÃO DE EMPRESAS DE TRANSPORTE DE COMUBUSTÍVEIS LÍQUIDOS

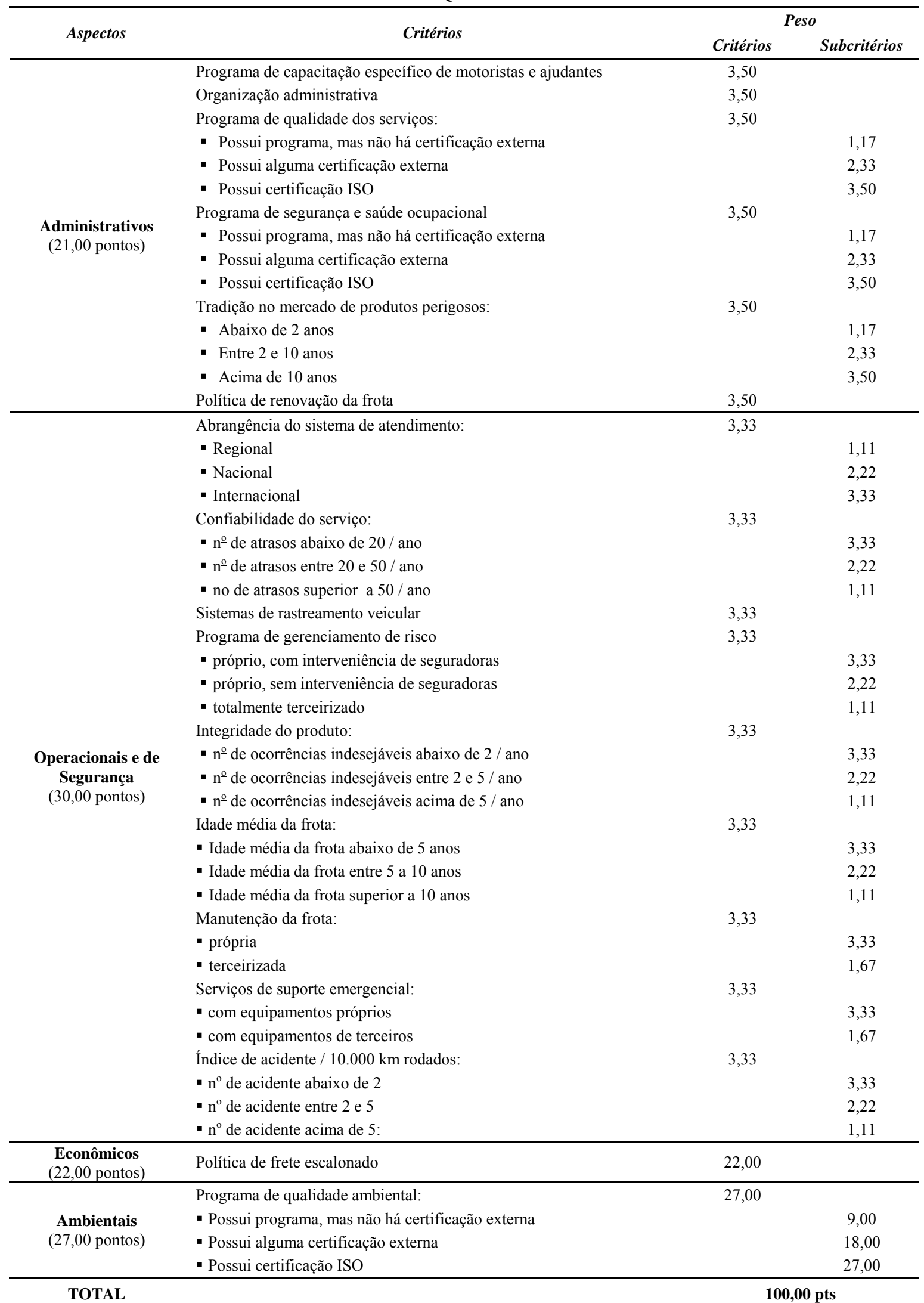

aos serviços prestados pelas suas dez transportadoras na região Centro-Oeste. O resultado obtido permitiu medir os gaps entre importância/satisfação média em relação a cada critério, fornecendo informações sobre os aspectos que podem ser aperfeiçoados para a melhoria dos serviços. A Tabela 8 ilustra os resultados.

Os critérios que merecem um maior cuidado por parte da empresa transportadora são os que apresen- 
Tabela 6. Tabela de classificação das empresas de transporte de combustíveis líquidos

\begin{tabular}{lc}
\hline \multicolumn{1}{c}{ Classificação } & Total de Pontos \\
\hline Altíssimo risco & $0,00<$ total $\leq 40,00$ \\
Alto risco & $40,00<$ total $\leq 60,00$ \\
Moderado Risco & $60,00<$ total $\leq 80,00$ \\
Baixo Risco & $80,00<$ total $\leq 100,00$ \\
\hline
\end{tabular}

Tabela 7. Classificação das empresas de transporte de combustíveis líquidos contratadas pela Petrobras Distribuidora em relação ao risco

\begin{tabular}{lc}
\hline \multicolumn{1}{c}{ Classificação } & Número de empresas \\
\hline Altíssimo risco & 0 \\
Alto risco & 0 \\
Moderado Risco & 6 \\
Baixo Risco & 4 \\
\hline
\end{tabular}

tam gaps negativos, a saber: Programa de Segurança e Saúde Ocupacional, Sistema de Rastreamento Veicular, Programa de Gerenciamento de Risco, equipamentos próprios de atendimento emergencial e Programa de Qualidade Ambiental.

Os critérios que merecem um maior cuidado por parte da empresa transportadora são os que apresentam gaps negativos, a saber: Programa de Segurança e Saúde Ocupacional, Sistema de Rastreamento Veicular, Programa de Gerenciamento de Risco, equipamentos próprios de atendimento emergencial e Programa de Qualidade Ambiental.

\section{CONCLUSÕES E RECOMENDAÇÕES FINAIS}

O presente trabalho atendeu ao seu objetivo inicial, propondo uma metodologia de classificação de empresas de transporte rodoviário de combustíveis líquidos, de forma a oferecer ao embarcador uma ferramenta de apoio à tomada de decisão no processo de contratação de uma transportadora. Também, permitiu o uso da ferramenta para avaliar os gaps de importância/satisfação médios em relação ao serviço das transportadoras de combustíveis líquidos contratadas.

A metodologia proposta não é rígida, uma vez que permite a exploração de cenários, cada qual com seus atores, os quais podem eleger e valorar seus critérios de acordo com a conjuntura vivenciada. Recomendam-se, para futuros trabalhos, estudos para a pormenorização de subcritérios, bem como de sua valoração; ou, ainda, conforme a necessidade, a inclusão de maior número de critérios, elencados pelos diversos atores do setor.

Vale ressaltar que a metodologia proposta neste trabalho pode, com pequenas adequações, ser utilizada para a classificação de transportadores de outros tipos de mercadorias.

\section{REFERÊNCIAS BIBLIOGRÁFICAS}

ABIQUIM (2006). Relatório de Atuação Responsável. Associação Brasileira da Ind. Química, São Paulo, SP.

ANP (2006). Anuário Estatístico Brasileiro do Petróleo, Gás Natural e Biocombustíveis 2006. Agência Nacional do Petróleo, Brasília, DF.

ANTT (2004). Resolução no 420, aprova as Instruções Complementares ao Regulamento do Transporte Terrestre de Produtos Perigosos. Agência Nacional de Transportes Terrestres, Brasília, DF.

ANTT (2006). Anuário Estatístico 2006 - Ano Base 2005 (Dados Preliminares). Agência Nacional de Transportes Terrestres, Brasília, DF.

CETESB (2007). Relatório de Emergências Químicas Atendidas pela CETESB em 2006. Companhia de Tecnologia de Saneamento Ambiental do Estado de São Paulo, São Paulo, SP.

Dumit, C. (2005). O Transporte Ferroviário de Carga no Brasil: Estudo de Caso do Transporte de Combustíveis na Região Sul. Dissertação de Mestrado em Engenharia Industrial. PUC-RJ.

EPE (2006). Política Nacional de Biocombustíveis. Empresa de Pesquisa Energética, Rio de Janeiro, RJ.

EIA (2005). International energy outlook: 2005. Energy Information Administration. Department of Energy, Washington, US.

Freitas, A.L. P.; Costa, H. G. (2000). A Classificação da Qualidade de Serviços: Um Tratamento Multicritério. III Simpósio de Administração da Produção, Logística e Operações Internacionais. São Paulo, SP.

Gheorghe, A. V. (2006). Systems Enginnering Approach to Risk and Vulnerability Management of Transport Dangerous Goods. Instituto Federal de Tecnologia. Zurique, Suíça.

Guidoni, R. (2005). Reportagem Com os Dias Contados. Revista Combustíveis, ed. 24. Fecombustíveis, RJ.

Hartman, L. C. (2003). Uma Metodologia para Avaliação do Risco do Transporte de Produtos Perigosos por Meio Rodoviário. Dissertação de Mestrado, Faculdade de Engenharia Civil, Universidade Estadual de Campinas. Campinas, SP.

Harwood, W. D., Viner, G. J. e Russel, R. E. Characteristics of Accidents an Incidents in Highway Transportation of Hazardous Materials. Transportation Research Record n. 1245, pp. 23-33. Washington, DC.

Lieggio Júnior, M. (2006). Transporte Rodoviário de Produtos Perigosos: Análise das Principais Propostas de Atualização à Portaria MT no. 349/02. Monografia de Especialização em Regulação de

Tabela 8. Gaps entre os graus de importância/satisfação médios em relação ao serviço das transportadoras de combustíveis líquidos contratadas pela Petrobras Distribuidora

\begin{tabular}{|c|c|c|c|c|}
\hline Aspectos & Critérios & $\begin{array}{c}\text { Grau de } \\
\text { importância }\end{array}$ & $\begin{array}{c}\text { Grau de } \\
\text { satisfação } \\
\text { médio }\end{array}$ & Gap \\
\hline \multirow{4}{*}{ Administrativos } & Programa de segurança e saúde ocupacional & 5 & 4 & -1 \\
\hline & Política de renovação da frota & 4 & 4 & 0 \\
\hline & Confiabilidade no serviço & 4 & 4 & 0 \\
\hline & Sistema de rastreamento veicular & 5 & 3,33 & $-1,7$ \\
\hline \multirow{4}{*}{$\begin{array}{l}\text { Operacionais e } \\
\text { de Segurança }\end{array}$} & Programa de gerenciamento de risco & 5 & 4 & -1 \\
\hline & Integridade do produto & 4 & 4 & 0 \\
\hline & Programa de manutenção da frota & 4 & 4 & 0 \\
\hline & Equipamentos próprios de atendimento emergencial & 5 & 3,22 & $-1,8$ \\
\hline \multirow{2}{*}{ Meio Ambiente } & Programa de qualidade ambiental & 5 & 4 & -1 \\
\hline & Tratamento dos efluentes & 4 & 4 & 0 \\
\hline
\end{tabular}


Transportes Terrestres, UFRJ. Rio de Janeiro, RJ.

Likert, R. (1967). The Human Organization: Its Management and Value. Mc-Graw-Hill, 258 pp. EUA, New York.

Oliveira, D. P. R. Planejamento Estratégico. Editora Atlas. São Paulo, SP.

Pijawka, K. D.; Foote, S.; e Soelsilo, A. (I985). Risk Assesment of Transporting Hazardous Material: Route Analysis and Hazard Management. Transport Research Record n. 1020, Transport, pp. 01-06. Washington, DC

Porath, R., Costa; F. J. B., Silva; V. A., Mello, M. A. S; Bicca, V. H. F.; e Nascimento, S. N. (2005). Modelo de Análise de Risco para Classificação da Periculosidade de Rotas de Transporte de Produtos Perigosos com Uso de Procedimentos de MCDA. 10。 Encontro Nac. de Conservação Rodoviária. Joinville, SC.

Rhyne, R. W. (1994). Hazardous Materials Transportation Risk: Quantitative Approaches for Truck and Train. Van No strand Reinhold, 254p. New York, NY.

Scalon, D. R.; e Cantilli, J. E. (1985). Assessing the Risk and Safety in the Transportation of Hazardous Materials. Transportation Research Board n. 1020, pp. 06-11. Washington, DC.

Ramos, F. B. (1997). Metodologia para Escolha de Alternativas de Rotas para o Transporte de Materiais Perigosos. Dissertação de Mestrado, Escola de Engenharia de Produção, UFSC. Florianópolis, $\mathrm{SC}$.

SINDICOM (2007). Disponível em: <http://www.sindicom.com.br $>$ Acesso em: 20 jun. 2007.

Verter, V. e Kara, B. Y. (2001). A GIS-Based Framework for Hazardous Materials Transport Risk Assessment, vol. 21, n. 6, pp. 11091120, EUA. 